\title{
ANTHOLOGY \\ Divorce: Evidence from Florida Counties
}

\author{
CHARLES GODWARD, JOHN A. LIST, AND MARK THOMPSON \\ University of Central Florida
}

In 1994 the estimated number of couples that married in the U.S. was 2.3 million, while nearly 1.2 million divorces were granted. Although the divorce rate has decreased since 1980, it remains at twice the annual rate of the mid-1960s. Changing roles of women and labor markets and a shift in social norms and values have been hypothesized as the main catalysts behind rising divorce rates. A complementary explanation is the outside option theory, which suggests that divorce is a function of utility within and outside marriage [Moffitt, JPE, 1990].

Although the above theories represent plausible explanations of divorce, empirical evidence indicates the issue is largely unsettled. This paper attempts to shed further light on the causes of divorce using Florida quinquennial county data from 1980-95. The model considers the divorce rate $(D I V \%)$ as a function of: 1) percentage of white population (WPOP); 2) real per capita income (INC); and 3) welfare benefits, measured as real dollars of Aid-to-Families-withDependent-Children $(A F D C)$ per year per case $(A F D C A S E)$. County- and time-specific dummy variables are also included to account for time-invariant county effects and county-invariant period effects. Thus, the model estimated is:

$$
D i v_{i t}=\beta_{1 i}+\beta_{1 i}+\sum_{2}^{k} \beta_{k} X_{k i t}+\varepsilon_{i t}
$$

where: $\beta_{1 i}$ and $\beta_{1 t}$ represent fixed county and period effects; $X_{k i t}$ is an exogenous variable; and $\varepsilon_{i t}$ represents the random error term. All data were obtained from various years of the Florida Statistical Abstract (1980-96).

Following previous studies, the authors expect the percentage of the white population [U.S. Department of Health and Human Resources, 1990] and income [Becker, JPE, 1973] to negatively affect divorce rates, while welfare benefits should be positively related [Moffitt, JPE, 1990]. This implies that married people consider their outside options when contemplating divorce. The estimated regression, corrected for groupwise heteroskedasticity $\left(\chi^{2}(66)=154,175\right)$, is:

$$
\begin{gathered}
D i v_{i t}-.83 E-02-.36 E-02 \text { WPOP }-.85 E-07 I N C+.87 E-06 \text { AFDCASE } \\
(8.97)(-3.50)
\end{gathered}
$$

where t-statistics are in parentheses. All coefficients are as hypothesized and significant at the 1 percent level. Results imply a larger white population leads to lower divorce rates. Also, estimates suggest relatively richer counties experience lower divorce rates than poorer counties. Finally, welfare benefits are positively related to divorce rates, lending credence to the outside income theory. Although AFDC was initially established to provide support for one-parent families, findings from the groupwise heteroskedastic model suggest welfare benefits may be an incentive for divorce. This result contradicts policymaker's initial intent and may suggest that AFDC funding is sending erroneous signals to lesser privileged married couples. 